\title{
Artificial Intelligence Techniques for Distance Education: A Systematic Literature Review
}

\author{
Aayat Aljarrah ${ }^{1}$, Mustafa Ababneh ${ }^{1}$, Damla Karagozlu ${ }^{2}$, Fezile Ozdamli ${ }^{2}$ \\ ${ }^{1}$ Near East University, Department of Computer Information Systems, Nicosia 99138, Cyprus \\ ${ }^{2}$ Near East University, Computer Information Systems Research and Technology Centre,
} Nicosia 99138, Cyprus

\begin{abstract}
In the current era, education, like other fields, relies heavily on big data. Moreover, artificial intelligence, including affective computing, is one of the most essential and popular technologies adopted by educational institutions to process and analyze big data. In this systematic review, many previous research types related to improving educational systems using artificial intelligence techniques were studied, such as: deep learning, machine learning, and affective computing. This systematic review aims to identify the gaps in students' emotional understanding in distance education systems. The world has recently witnessed the spread of educational processes for distance learning, especially in the university and the enormous open online courses (MOOCs). Besides, the COVID-19 pandemic has been involved in changing all educational processes to a distance learning system. The results indicated that these systems recorded a high success rate. However, the teacher does not fully understand the student's emotional state during the educational session. It also lacks monitoring or monitoring during the electronic exams, which are electronic exams. So, it is a widespread problem in distance learning.
\end{abstract}

DOI: $10.18421 /$ TEM104-18

https://doi.org/10.18421/TEM104-18

Corresponding author: Aayat Aljarrah, Near East University, Department of Computer Information Systems, Nicosia 99138, Cyprus. Email:20194007@std.neu.edu.tr

Received: 02 August 2021.

Revised: 01 October 2021.

Accepted: 08 October 2021.

Published: 26 November 2021.

(c))BY-NC-ND (C) 2021 Aayat Aljarrah et al; published by UIKTEN. This work is licensed under the Creative Commons Attribution-NonCommercial-NoDerivs 4.0 License.

The article is published with Open Access at www.temjournal.com
Keywords - Face recognition; Machine learning; Convolutional Neural Network; Image processing; Emotion detection; Distance learning; artificial intelligence.

\section{Introduction}

Referring to the technological development nowadays, education has a considerable percentage from it. The distance learning systems achieved significant growth by measuring them through the internet. Besides, the spread of the coronavirus (COVID-19) has led most cities in the world to apply distance learning for all the educational institutions [1], to make sure about the continuity of the educational process regularly without affecting students' education because of this pandemic. This pandemic of COVID-19 freshens the significance of massive open online courses (MOOCs) courses [1], where academic life after this pandemic will change entirely during the next period. Due to that reason, education through the internet is strongly enforced in such circumstances, especially by the presence of technology that regularly develops day by day [2].

Nevertheless, the use of distance learning system is facing many challenges. It is considered an unfriendly way of learning when it comes to the learner [3]. For example, it considers all learners equal regardless of their levels [4] during the learning session. Also, it does not care about the understanding rate for learners or their feelings during the sessions. The lack of understanding of information during the lectures makes the learners confused, bored, and exhausted, which decreases their ability to study [1]. Also, they feel tired of not understanding the lessons, leading them to suffering from different moods and feelings. As a result, this makes the learner depressed, pessimistic, disordered, and angry [5], which decreases their performance and distracts them from other directions due to losing their interest in educational sessions.

Thus, the system does not understand these emotions like face-to-face learning. Meeting students facilitates the teacher to recognize the emotional and psychological changes with the teachers' experience, 
knowledge, and perception. Thus, based on these changeable feelings that the teacher acknowledges, he can choose the appropriate way or technique. Picard et al. classified feelings in computing; besides that, they suggested emotion detection in 1994 [6]. In addition to classifications of feelings, there are many aspects to be considered in the artificial simulation of social interactions that consider the role of emotions. Some of them are the physical expression of emotions and the simulation of emotional behavior. Emotional computing is regarded as the field of research responsible for studying these phenomena, as its tasks include identifying emotions in texts, sound, and images, expressing feelings through facial expressions or gestures, and creating models that simulate the emergence of emotions or the influence of emotions on decision-making, among other things [5], [6].

Mukhopadhyay et al. classified emotions into 4 classes: fear, anger, sadness, and happiness, besides created an algorithm to discover the seven main feelings (surprise, fear, disgust, anger, happiness, sadness, and neutral) [5]. Mainly, the two problems of understanding the students' emotions and evaluating them in the electronic exams are considered as the major problems that educational institutions may face in the distance learning systems. That may happen because of the difficulty of analyzing the emotions in real-time and for the difficulty of monitoring students in a well-done way. Eventually, the lack of emotional interaction between the teacher and the learner affects seriously the process of learning [7], [8].

With the rapid changes and developments in the world of technology, especially in the field of artificial intelligence, machine learning, and deep learning, it has become possible to train machine learning and deep learning models to guide the students, know students' feelings and reactions [8], [9].

Although there is a diversity and spread in the researches that have been conducted to develop distance learning systems, there is still a lack of understanding of the teacher to the learner, whether he is happy or dispersed during the educational session and other many feelings because there is a distance between them, also the teacher's focus is distributed between the student and information that he explains to the learner using the latest methods. Therefore, this study aims to identify emotion computing techniques and their role in developing distance education systems by reviewing several previous studies and making future suggestions to solve the obtained gaps. As a result, three questions were asked in this study to fill in these gaps:
1. How do artificial intelligence systems contribute to analyzing the textual emotions of students?

2. How are the face recognition techniques supporting e-learning systems?

3. What are the common artificial intelligence algorithms in face recognition of real-time?

4. What are the common face recognition obstacles in real-time?

5. What are the common emotion recognition datasets in education?

The paper structure is structured as follows: In the first section, we will provide a short review of the literature related to face recognition systems, algorithms, and techniques used. Next, we will explain the techniques used to do this study. Then, we will discuss and analyze the essential research to identify the gaps in these researches. Finally, we will present the results of this study, and suggest some solutions.

\section{Literature Review}

This section will provide many significant works in recognizing faces containing three main parts: face recognition, discovering the features, and facial passivity [10]. Nowadays, many researches are done based on the deep learning technique to find the passivity and the emotions during distance education systems by analyzing the texts, and analyzing the face [11]. Table 1 summarizes many works related to this topic.

Table 1. Summarizes of works related to this topic

\begin{tabular}{|c|c|c|}
\hline $\begin{array}{l}\text { Authors } \\
\text { / year }\end{array}$ & Aims & Technique \\
\hline 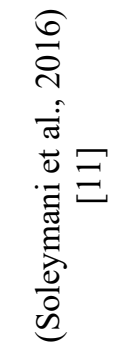 & $\begin{array}{l}\text { This study aims to } \\
\text { immediately detect the } \\
\text { emotions of video } \\
\text { viewers using signals } \\
\text { from the } \\
\text { electroencephalogram } \\
\text { (EEG) and facial } \\
\text { expressions. }\end{array}$ & $\begin{array}{l}\text { Long-short-term- } \\
\text { memory recurrent } \\
\text { neural networks } \\
\text { (LSTM-RNN) and } \\
\text { continuous conditional } \\
\text { random fields (CCRF) }\end{array}$ \\
\hline 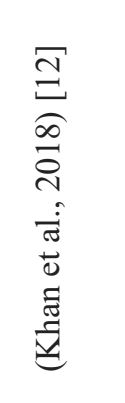 & $\begin{array}{l}\text { This study aims to } \\
\text { create an algorithm } \\
\text { based on analyzing the } \\
\text { expressions of the } \\
\text { driver's face if the } \\
\text { driver is exhausted or } \\
\text { drowsy and is based } \\
\text { on issuing an alert to } \\
\text { the driver in these } \\
\text { cases. }\end{array}$ & $\begin{array}{l}\text { Artificial neural } \\
\text { networks (ANN) } \\
\text { k-nearest neighbors' } \\
\text { algorithm (KNN) } \\
\text { Support vector } \\
\text { machine (SVM) }\end{array}$ \\
\hline
\end{tabular}




\begin{tabular}{|c|c|c|}
\hline 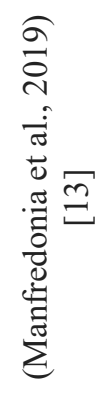 & $\begin{array}{l}\text { This research aims to } \\
\text { diagnose individuals } \\
\text { with an autism } \\
\text { spectrum disorder to } \\
\text { produce facial } \\
\text { expressions of } \\
\text { emotions in response } \\
\text { to a verbal claim by } \\
\text { analyzing their facial } \\
\text { expressions. }\end{array}$ & $\begin{array}{l}\text { facial expression } \\
\text { analysis software } \\
\text { (FACET) }\end{array}$ \\
\hline 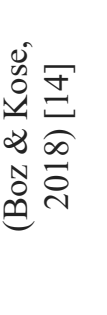 & $\begin{array}{l}\text { This research aims to } \\
\text { design and develop a } \\
\text { system that can extract } \\
\text { emotions from } \\
\text { individual facial } \\
\text { expressions in general. }\end{array}$ & $\begin{array}{l}\text { Artificial Neural } \\
\text { Network model } \\
\text { trained by a recent } \\
\text { optimization } \\
\text { algorithm called as } \\
\text { Vortex Optimization } \\
\text { Algorithm } \\
\text { Intellectual }\end{array}$ \\
\hline 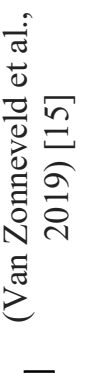 & $\begin{array}{l}\text { This study aimed to } \\
\text { build a system for } \\
\text { facial recognition and } \\
\text { emotional behavior to } \\
\text { discover children at } \\
\text { risk of developing } \\
\text { future criminal } \\
\text { behavior. }\end{array}$ & $\begin{array}{l}\text { functioning such as } \\
\text { the Wechsler } \\
\text { Intelligence Scale for } \\
\text { Children (WISC). } \\
\text { Two subtests, Block } \\
\text { (Design and } \\
\text { Vocabulary) and full- } \\
\text { scale intelligence } \\
\text { quotient (FSIQ) }\end{array}$ \\
\hline 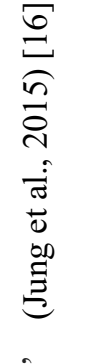 & $\begin{array}{l}\text { This study attempts to } \\
\text { apply deep learning } \\
\text { techniques to } \\
\text { recognize facial } \\
\text { expressions that } \\
\text { represent human } \\
\text { emotions using Haar- } \\
\text { like features } \\
\text { In this study, a method }\end{array}$ & $\begin{array}{l}\text { convolutional neural } \\
\text { network and deep } \\
\text { neural network. }\end{array}$ \\
\hline 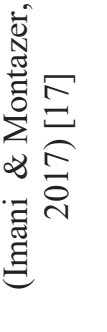 & $\begin{array}{l}\text { for identifying } \\
\text { feelings from facial } \\
\text { images was suggested, } \\
\text { which can recognize } \\
\text { seven feelings of a } \\
\text { person, i.e., six basic } \\
\text { expressions in } \\
\text { addition to neutral. }\end{array}$ & $\begin{array}{l}\text { GLCM approach for } \\
\text { feature extraction and } \\
\text { the nearest neighbor } \\
\text { (NN) for classification } \\
\text { also used The fuzzy } \\
\text { Euclidean distance }\end{array}$ \\
\hline 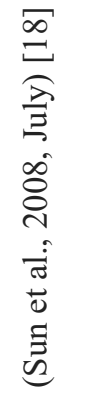 & $\begin{array}{l}\text { In this research, a } \\
\text { model based on } \\
\text { affective computing } \\
\text { has been proposed that } \\
\text { takes facial features as } \\
\text { input data to estimate } \\
\text { learners' emotional } \\
\text { state in the modern } \\
\text { distance education } \\
\text { system. }\end{array}$ & $\begin{array}{l}\text { support vector } \\
\text { machine (SVM) } \\
\text { algorithm }\end{array}$ \\
\hline 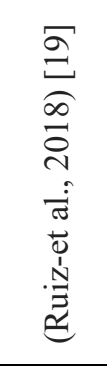 & $\begin{array}{l}\text { In this study, a system } \\
\text { has been proposed to } \\
\text { provide an emotional } \\
\text { recognition of human } \\
\text { facial expressions for } \\
\text { application to a robot } \\
\text { in real-time }\end{array}$ & $\begin{array}{l}\text { This model combines } \\
\text { a Deep Convolutional } \\
\text { Neural Network } \\
(\mathrm{CNN}) \text { for self- } \\
\text { learned feature } \\
\text { extraction and a } \\
\text { Support Vector } \\
\text { Machine (SVM) for } \\
\text { emotion classification. }\end{array}$ \\
\hline
\end{tabular}

\begin{tabular}{|c|c|c|}
\hline 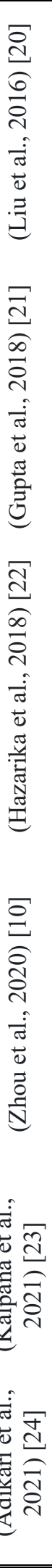 & 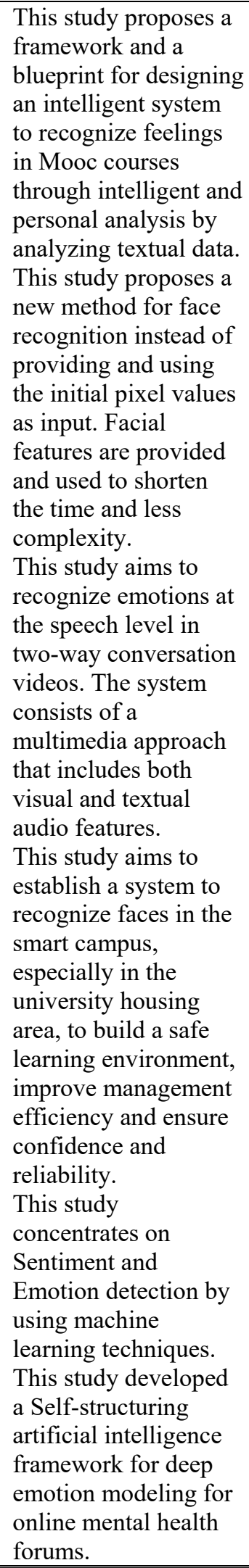 & $\begin{array}{l}\text { Unsupervised emotion } \\
\text { latent representations } \\
\text { and classification } \\
\text { using GSOM. }\end{array}$ \\
\hline
\end{tabular}

\section{The Method}

This section provides the used technique to do the study by following the systematic review principles using the protocol Preferred Reporting Items for Systematic Reviews and Meta-Analyses (PRISMA). It is used to get the final result by summarizing the 
reported and restricted literature findings in a specific research area [25]. The protocol consists of 4 stages of a flowchart: identification, examination, eligibility, and inclusiveness. It is instrumental to continuously and accurately report systematic reviews and meta-analysis. By using the protocol, the final results will be free from prejudices in the review studies. However, it is undeniable that most reviews may suffer from reporting selective results [25].

\subsection{Research Mechanics}

This section specifically applied the four stages flow chart. First, the resources of articles will be specified and followed by sorting the search results. Then, seeking for duplicates and irrelevant articles is done based on their titles and summaries. After that, the full-text papers based on the eligibility criteria will be excluded in order to receive the included ones for further analysis.

\subsection{Databases and Inclusion Criteria}

The two databases, including; Google Scholar and Web of Science, are considered as tools for searching all retrieving academic articles about the related topics based on logical queries such as:

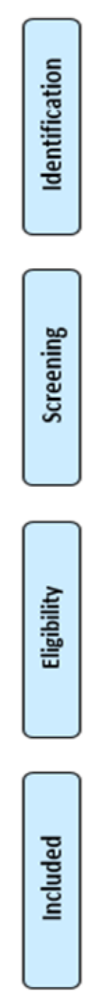

*Google Scholar query: "Face Emotion Recognition" for all years and the total researches are 1480 articles.

*Search query for Web of Science: TOPIC: ("Face Emotion Recognition") OR ("Emotion Recognition") and ("Artificial Intelligence") and ("E-Learning") or ("Distance Education") and ("image processing") for all years and the total researches are 643 articles.

According to the previously mentioned information that was inserted in the database, about 2123 articles related to this topic generally were found. Also, about 151 articles were deleted after duplicates, and then about 151 articles were screened specifically by sorting titles and summaries. In addition, almost 83 out of 151 articles were deleted after being screened. About 68 studies remained to be assessed for eligibility, and then 47 studies were excluded because 15 articles are talking in general which means they are not students' studies, 13 articles for voice recognition, and 19 articles did not have enough data. Finally, about 15 articles were included in the analysis in the current systematic review and the analysis study, besides summarizing their results as well. Figure 1 clarifies the flow chart of the PRISMA for this systematic review.

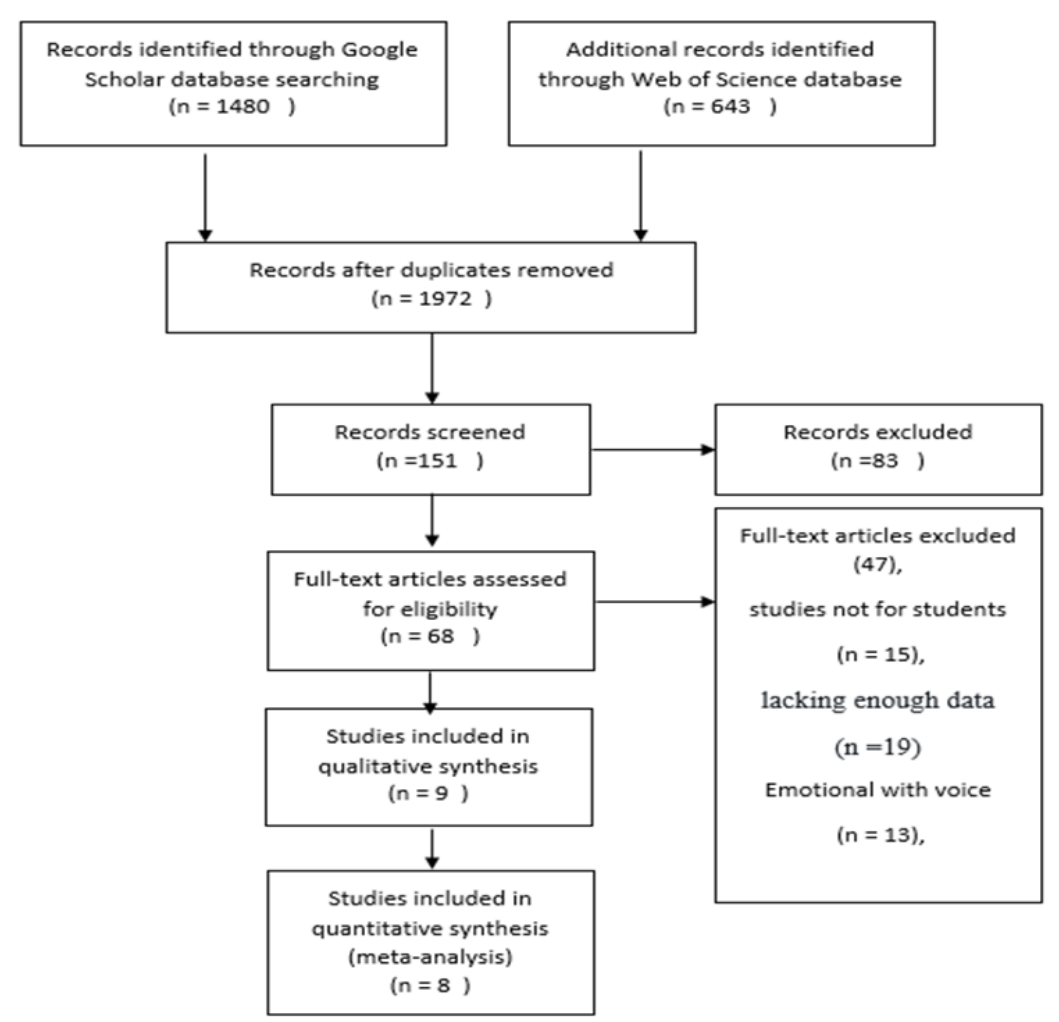

Figure 1. PRISMA Flowchart diagram for the current systematic review

\section{Results and Discussion}

This systematic review focused on 15 researches that work to create systems that contribute to enhancing learning by analyzing and understanding the emotions during distance education (see Table 2). 
Table 2. Analyzed papers

\begin{tabular}{|c|c|c|c|c|c|}
\hline 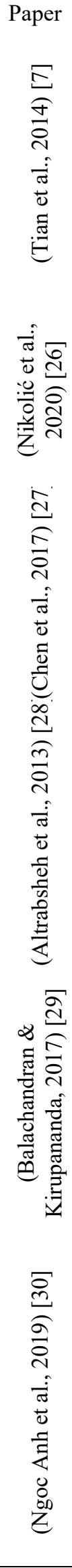 & 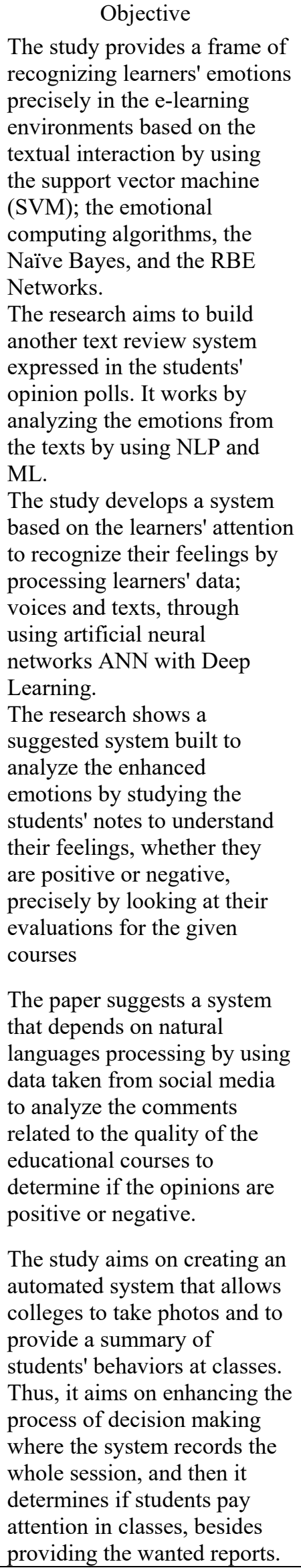 & $\begin{array}{l}\text { Support } \\
\text { vector } \\
\text { machine, } \\
\text { Naïve Bayes, } \\
\text { and the RBE } \\
\text { Networks. }\end{array}$ & 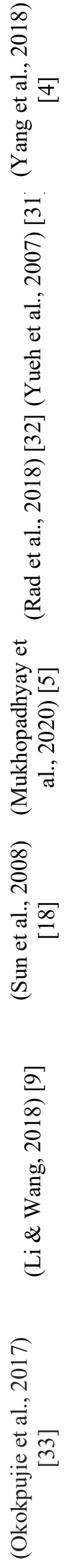 & 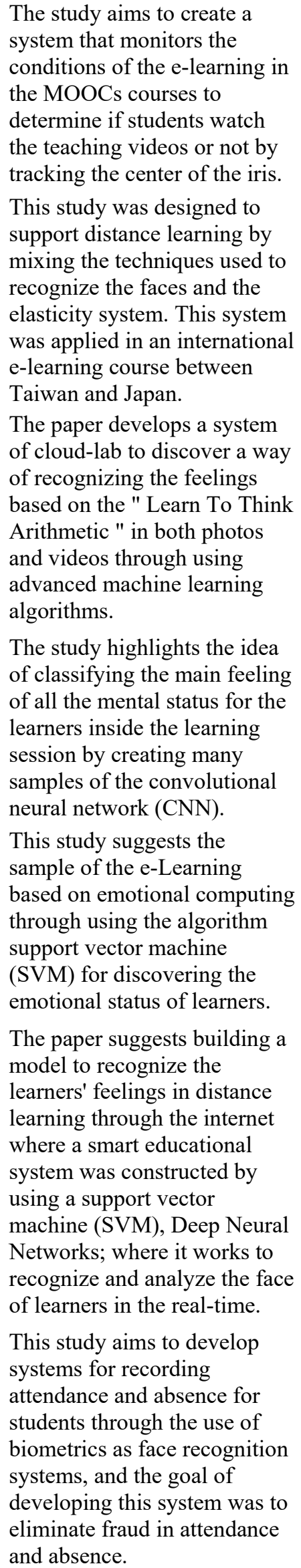 & $\begin{array}{l}\text { Support } \\
\text { vector } \\
\text { machine, } \\
\text { Deep Neural } \\
\text { Networks }\end{array}$ \\
\hline
\end{tabular}




\begin{tabular}{|c|c|c|}
\hline 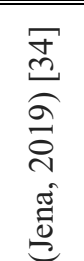 & $\begin{array}{l}\text { This paper contributes to } \\
\text { studying the emotion polarity } \\
\text { (positive, negative, or neutral) } \\
\text { of students and modeling and } \\
\text { predicting student feelings } \\
\text { using large databases. }\end{array}$ & $\begin{array}{l}\text { Machine } \\
\text { Learning } \\
\text { Algorithms }\end{array}$ \\
\hline 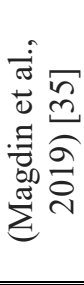 & $\begin{array}{l}\text { This study aims to develop a } \\
\text { system to analyze the } \\
\text { reactions captured by the face } \\
\text { analysis system and then } \\
\text { classified. This system has } \\
\text { been tested on } 50 \text { university } \\
\text { students. }\end{array}$ & $\begin{array}{l}\text { Facial Action } \\
\text { Coding } \\
\text { System } \\
\text { (FACS) }\end{array}$ \\
\hline
\end{tabular}

\section{Results and Discussion}

Emotional illiteracy (loss of understanding learners' emotions) in the e-Learning environment is considered as one of the famous problems someone faces during distance education. This issue, at present, has an increased significance by researchers because of the massive spread of the e-learning systems precisely after the COVID-19 pandemic. After using the artificial intelligence and machine learning technique, deep learning becomes the most famous used tool in developing educational systems. One of the most important techniques was smart emotional computing that works in analyzing learners' feelings to enhance the learning systems and increase the quality of students' performance.

\subsection{Contributions of Artificial Intelligence Systems to Analysis of Textual Emotions of Students}

Many researchers depended on analyzing the textual emotions for students [7], where the random forest algorithm achieved the best results in analyzing the textual emotions compared to the support vector machine (SVM) and Naïve Bayes. Also the analysis of textual emotions is limited to enhancing the students' performances, but it also aims to analyze the resulting feelings taken from students' opinion polls in different fields [26], [27]. To achieve the best results in analyzing the textual feelings, some algorithms have to be used: deep learning, artificial neural networks, natural language processing, and machine learning. The results show a high percentage of success in determining the emotions with $83 \%$ and $94 \%$ for positive feelings and negative ones, respectively. Also, many studies use machine learning algorithms to recognize students' feelings, either to study their polarity or with the purpose of modeling and predicting their feelings [34].

In addition, many studies made an analysis for notes and comments on electronic websites and on social media related to learners' opinions about a specific scientific course or about the university [27],
[29]. The primary purpose of the study was to determine if the opinions are positive or negative. Researchers extremely care about analyzing facial emotions since they are considered more expressed than textual ones. In many studies, the researchers developed systems that help analyze students' behaviors by analyzing the videos of the sessions for each student. Then, reports that clarify their behaviors are sent [30].

\subsection{Face Aecognition Techniques that Support e-Learning Systems}

In addition, one study developed systems that work to monitor the learners in MOOCs courses to know if the student is watching the educational video or not [4]. This system achieved a big success since it determines the center of the iris. Also, many other studies contributed to creating systems that are capable of supporting e-learning by using specific techniques that recognize faces [31], and discovering emotions through the learn to think arithmetic [32]. Also, several articles emphasize that face recognition in schools faces many social challenges and concerns that deserve special attention. In addition, many systems aimed to create facial recognition systems to review fraud and cheating in students' attendance by taking a large number of pictures of the student with different combinations and appearances and then sending them to the administrator. The system achieved accuracy in verifying the ratio from $70 \%$ to $90 \%$. This system made it clear that the more images in the database, the greater the accuracy [33].

\subsection{The Common Artificial Intelligence Algorithms in Face Recognition of Real-time}

Artificial intelligence algorithms are very important in the face recognition of real-time. Thus, some of the researchers used the learners' feelings recognition techniques through the learning session, and the first research suggests the sample of the eLearning based on emotional computing through 
using the algorithm support vector machine (SVM) for discovering the emotional status for learners [18], while the second research suggests a model which recognizes the learners' feelings in distance learning through the internet where a smart educational system was constructed by using a support vector machine (SVM), Deep Neural Networks; where it works to recognize and analyze the face of learners in the real-time [9]. Also, the third research highlights the idea of classifying the main feeling of all the mental status for the learners inside the learning session by creating many samples of the convolutional neural network (CNN) [5].

\subsection{The Common Emotion Recognition Datasets in the Education}

Nowadays, the Internet is a window for expressing opinions for users, where social media platforms such as Facebook, Twitter, and Instagram are a major source for mining text data, as students use it on a daily basis and in their daily activities to express their opinions, feelings, and reactions [7]. Also in another paper that is concerned with analyzing texts for students, the researcher collected comments from students at the Institute of Management Technology (IMT) Nagpur, India. This is done through the platforms (Twitter, Facebook, and MOODLE) [34].

The Internet is also the main source of huge data that researchers and analysts use in their studies and experiments, as one of the most important databases available for analyzing facial expressions over the Internet:

1. Facial expression recognition (FER_2013), which includes about 35,887 images. It contains about 28,709 samples for training, about 3589 samples for verification, and about 3589 samples for testing. It also contains the basic or key expressions that are categorized and provided for each sample, and it is frequently used to train CNN models [5], [9].

2. Cohn-Kanade AU-Coded Facial Expression which includes about 380 image sequences from 100 subjects. It also contains six main emotions in addition to the neutral ones [18].

3. Many of the systems depend on the databases created by the researchers to achieve their systems and train it, as Ngoc Anh collected his data by taking snapshots of students in lessons (the subject of basic programming) at FPT University [30]. Other researchers also recorded pictures of students in different poses with many facial expressions and collected them in the databases of their systems [31], [33], [35].

\subsection{The Common Face Recognition Obstacles in Real-time}

Face recognition problems are encouraging topic for research in the past and the present, despite a large number of research and proposals related to it, but there are still many limitations and problems faced by researchers, due to many reasons, including:

1) The student's sitting position and the angles of the body are difficult to explain whether the body is tilted or otherwise to judge if the student watches the video online or not [4], [30].

2) Lack of categorized reactions and feelings, as one of the expressions that do not find any similar classification which may appear [33], [35].

3) Facial expressions vary very quickly and with many different feelings [33].

4) The glasses worn by the student may reduce the detection of emotions [5].

5) Lighting is an important factor affecting the detection of feelings, whether the lighting is strong or weak [5].

This systematic review showed a lack in the researches that analyze feelings in real-time. However, they only work to analyze the learners' emotions, which creates a huge gap since there is no complete system to recognize and make sure of the learner's identity first, then understand their feelings step by step, and finally monitor students in exams. This reason is one of the most essential reasons that encouraged creating this systematic review. The second reason is the significant spread of e-learning systems at all educational levels. Finally, the significance of using the artificial intelligence techniques includes: convolutional neural networks $(\mathrm{CNN})$, deep neural networks (DNN), support vector machine (SVM), in analyzing emotions in real-time. According to this systematic review, a completed system is suggested to support the e-learning system consisting of 3 main parts: checking the student's identity, analyzing student's feelings in real-time with sending reports for the mental status of the learner, and supporting monitoring students in exams because of the lack of having supported studies in this field.

\section{Conclusion}

E-learning systems are becoming more and more popular nowadays. Emotions are essential factor in the learning process. It is a critical element in communication between teacher and learner and for evaluating learners. Recognizing the learner's feelings in the online learning scene and the Smart-E education system is also considered a multidisciplinary topic. 
In this paper, many types of research have been studied that use emotion computing by analyzing facial feelings in order to find solutions to problems faced by distance education systems, including the poverty of communication between the teacher and the learner and student evaluation and monitoring problems electronic exams. Moreover, it is not easy to recognize the face and analyze students' faces in real-time educational sessions with accuracy from the results obtained.

There are many ways to improve the analytical models of students' emotions. So, this study proposes to develop a system using a convolutional neural network to confirm the student's identity by recognizing his face and then analyzing the feelings of the learners during the online learning session in real-time. And finally, monitoring students in the exams ensures that they do not cheat, and thus the credibility of the examinations presented in distance learning systems increases.

\section{References}

[1]. Aljarrah, A. A., Ababneh, M. A. K., \& Cavus, N. (2020). The role of massive open online courses during the COVID-19 era: Challenges and perspective. New Trends and Issues Proceedings on Humanities and Social Sciences, 7(3), 142-152.

[2]. Goh, P. S., \& SANDARS, J. (2020). A vision of the use of technology in medical education after the COVID-19 pandemic. MedEdPublish, 1-8.

[3]. Mtebe, J. S., \& Raphael, C. (2018). Key Factors in Learners' Satisfaction with the E-Learning System at the University of Dar es Salaam, Tanzania. Australasian Journal of Educational Technology, 34(4), 107-122.

[4]. Yang, F., Jiang, Z., Wang, C., Dai, Y., Jia, Z., \& Hirota, K. (2018, December). Student eye gaze tracking during MOOC teaching. In 2018 Joint 10th International Conference on Soft Computing and Intelligent Systems (SCIS) and 19th International Symposium on Advanced Intelligent Systems (ISIS) (pp. 875-880). IEEE.

[5]. Mukhopadhyay, M., Pal, S., Nayyar, A., Pramanik, P. K. D., Dasgupta, N., \& Choudhury, P. (2020, February). Facial emotion detection to assess Learner's State of mind in an online learning system. In Proceedings of the 2020 5th International Conference on Intelligent Information Technology (pp. 107-115).

[6]. Picard, R. W. (2000). Affective computing. MIT press.

[7]. Tian, F., Gao, P., Li, L., Zhang, W., Liang, H., Qian, Y., \& Zhao, R. (2014). Recognizing and regulating elearners' emotions based on interactive Chinese texts in e-learning systems. Knowledge-Based Systems, 55, 148-164.

[8]. Ababneh, M., Aljarrah, A., Karagozlu, D., \& Ozdamli, F. (2021). Guiding the Students in High School by Using Machine Learning. TEM Journal,10(1), 384-391.
[9]. Agrawal, A., \& Mittal, N. (2020). Using CNN for facial expression recognition: a study of the effects of kernel size and number of filters on accuracy. The Visual Computer, 36(2), 405-412.

[10]. Soleymani, M., Asghari-Esfeden, S., Fu, Y., \& Pantic, M. (2015). Analysis of EEG signals and facial expressions for continuous emotion detection. IEEE Transactions on Affective Computing, 7(1), 17-28.

[11]. Zhou, W., Cheng, J., Lei, X., Benes, B., \& Adamo, N. (2020, July). Deep learning-based emotion recognition from real-time videos. In International Conference on Human-Computer Interaction (pp. 321-332). Springer, Cham.

[12]. Khan, S. A., Hussain, S., Xiaoming, S., \& Yang, S. (2018). An effective framework for driver fatigue recognition based on intelligent facial expressions analysis. Ieee Access, 6, 67459-67468.

[13]. Manfredonia, J., Bangerter, A., Manyakov, N. V., Ness, S., Lewin, D., Skalkin, A., ... \& Pandina, G. (2019). Automatic recognition of posed facial expression of emotion in individuals with autism spectrum disorder. Journal of autism and developmental disorders, 49(1), 279-293.

[14]. Boz, H., \& Kose, U. (2018). Emotion extraction from facial expressions by using artificial intelligence techniques. BRAIN. Broad Research in Artificial Intelligence and Neuroscience, 9(1), 5-16.

[15]. Van Zonneveld, L., De Sonneville, L., Van Goozen, S., \& Swaab, H. (2019). Recognition of facial emotion and affective prosody in children at high risk of criminal behavior. Journal of the International Neuropsychological Society, 25(1), 57-64.

[16]. Jung, H., Lee, S., Park, S., Kim, B., Kim, J., Lee, I., \& Ahn, C. (2015, January). Development of deep learning-based facial expression recognition system. In 2015 21st Korea-Japan Joint Workshop on Frontiers of Computer Vision (FCV) (pp. 1-4). IEEE.

[17]. Imani, M., \& Montazer, G. A. (2017, October). GLCM features and fuzzy nearest neighbor classifier for emotion recognition from face. In 2017 7th International Conference on Computer and Knowledge Engineering (ICCKE) (pp. 8-13). IEEE.

[18]. Sun, J. M., Pei, X. S., \& Zhou, S. S. (2008, July). Facial emotion recognition in modern distant education system using SVM. In 2008 International Conference on Machine Learning and Cybernetics (Vol. 6, pp. 3545-3548). IEEE.

[19]. Ruiz-Garcia, A., Elshaw, M., Altahhan, A., \& Palade, V. (2018). A hybrid deep learning neural approach for emotion recognition from facial expressions for socially assistive robots. Neural Computing and Applications, 29(7), 359-373.

[20]. Liu, Z., Zhang, W., Sun, J., Cheng, H. N., Peng, X., \& Liu, S. (2016, September). Emotion and associated topic detection for course comments in a MOOC platform. In 2016 International Conference on Educational Innovation through Technology (EITT) (pp. 15-19). IEEE.

[21]. Gupta, P., Saxena, N., Sharma, M., \& Tripathi, J. (2018). Deep neural network for human face recognition. International Journal of Engineering and Manufacturing (IJEM), 8(1), 63-71. 
[22]. Hazarika, D., Poria, S., Zadeh, A., Cambria, E., Morency, L. P., \& Zimmermann, R. (2018, June). Conversational memory network for emotion recognition in dyadic dialogue videos. In Proceedings of the conference. Association for Computational Linguistics. North American Chapter. Meeting (Vol. 2018, p. 2122). NIH Public Access.

[23]. Kalpana, G., Kumar, P., Sudhakar, J., \& Sowndarya, P. (2021). Emotion and Sentiment Analysis using Machine Learning. Annals of the Romanian Society for Cell Biology, 1906-1911.

[24]. Adikari, A., Gamage, G., De Silva, D., Mills, N., Wong, S. M. J., \& Alahakoon, D. (2021). A self structuring artificial intelligence framework for deep emotions modeling and analysis on the social web. Future Generation Computer Systems, 116, 302315.

[25]. Liberati, A., Altman, D. G., Tetzlaff, J., Mulrow, C., Gøtzsche, P. C., Ioannidis, J. P., ... \& Moher, D. (2009). The PRISMA statement for reporting systematic reviews and meta-analyses of studies that evaluate health care interventions: explanation and elaboration. Journal of clinical epidemiology, 62(10), e1-e34.

[26]. Nikolić, N., Grljević, O., \& Kovačević, A. (2020). Aspect-based sentiment analysis of reviews in the domain of higher education. The Electronic Library, 38(1), 44-64.

[27]. Chen, H., Dai, Y., Feng, Y., Jiang, B., Xiao, J., \& You, B. (2017). Construction of affective education in mobile learning: The study based on learner's interest and emotion recognition. Computer Science and Information Systems, 14(3), 685-702.

[28]. Altrabsheh, N., Gaber, M. M., \& Cocea, M. (2013). SA-E: sentiment analysis for education. Frontiers in Artificial Intelligence and Applications, 255, 353-362.
[29]. Balachandran, L., \& Kirupananda, A. (2017, December). Online reviews evaluation system for higher education institution: An aspect based sentiment analysis tool. In 2017 11th international conference on software, knowledge, information management and applications (SKIMA) (pp. 1-7). IEEE.

[30]. Ngoc Anh, B., Tung Son, N., Truong Lam, P., Le Chi, P., Huu Tuan, N., Cong Dat, N., ... \& Van Dinh, T. (2019). A computer-vision based application for student behavior monitoring in classroom. Applied Sciences, 9(22), 4729.

[31]. Yueh, H. P., Liu, Y. L., Lin, W. J., Shoji, T., \& Minoh, M. (2007, July). Integrating face recognition techniques with blog as a distance education support system (DESS) in international distance learning. In Seventh IEEE International Conference on Advanced Learning Technologies (ICALT 2007) (pp. 507-511). IEEE.

[32]. Rad, P., Roopaei, M., Beebe, N., Shadaram, M., \& $\mathrm{Au}, \mathrm{Y}$. (2018, January). AI thinking for cloud education platform with personalized learning. In Proceedings of the 51st Hawaii international conference on system sciences.

[33]. Okokpujie, K., Noma-Osaghae, E., John, S., \& Oputa, R. (2017, October). Development of a facial recognition system with email identification message relay mechanism. In 2017 international conference on computing networking and informatics (ICCNI) (pp. 1-6). IEEE.

[34]. Jena, R. K. (2019). Sentiment mining in a collaborative learning environment: capitalising on big data. Behaviour \& Information Technology, 38(9), 986-1001.

[35]. Magdin, M., Benko, L', \& Koprda, Š. (2019). A case study of facial emotion classification using affdex. Sensors, 19(9), 2140. 